\title{
Atmospheric Pollution with Halothane during Outpatient Dental Anaesthesia
}

\author{
LEO STRUNIN, J. M. STRUNIN, C. C. MALLIOS
}

British Medical fournal, 1973, 4, 459-460

\begin{abstract}
Summary
Pollution of the atmosphere with halothane has been measured during general anaesthesia for outpatients undergoing dental extractions. The level of contamination was far in excess of that recorded in surgical operating theatres, and halothane was inhaled at similar concentrations by both the anaesthetist and the dental surgeon. The room air-changing system and a local fan had little effect on contamination. Scavenging devices on the exhalation valve of the anaesthetic circuit were only moderately effective in reducing the concentration of halothane in the atmosphere.
\end{abstract}

\section{Introduction}

A number of studies have associated atmospheric pollution by volatile anaesthetic agents with various toxic effects in operatingroom personnel (Vaisman, 1967; Askrog and Harvald, 1970; Cohen et al., 1971; Knill-Jones et al., 1972). Halothane has been the most commonly measured contaminant, with typical average levels of 10 to 15 p.p.m. (0.001-0.0015\%). These levels were measured when anaesthesia was administered using circuits where the only leak to the atmosphere was via an exhalation valve. Under these circumstances the anaesthetist, who is usually nearest the exhalation valve, will inhale the highest concentrations, and other personnel the average value for the whole operating area. Simple ducting of exhaled gases from the patient, therefore, may greatly reduce both the concentration inhaled by the anaesthetist and the overall level of pollution.

Outpatient anaesthesia for dental extraction using halothane is probably the single most common form of general anaesthesia administered in Great Britain. For example, in the Dental School at King's College Hospital some 5,000 patients a year undergo anaesthesia in the dental chair, compared with some 10,000 anaesthetics a year in a large general hospital. During dental anaesthesia pollution of the atmosphere occurs both from the exhalation valve and through the patient's mouth. As the anaesthetist and the dentist are in very close proximity to the patient's head both may inhale high concentrations of halothane. We have measured halothane contamination of the atmosphere during dental anaesthesia and studied some factors influencing pollution in these circumstances.

\section{Materials and Methods}

\section{ANAESTHETIC AND SURGICAL TECHNIQUES}

The study was carried out during the general anaesthetic sessions for dental extraction in the outpatient department of the dental

Anaesthetic Department, King's College Hospital, London SE5 9RS LEO STRUNIN, M.B., F.F.A. R.C.S., Senior Lecturer

J. M. STRUNIN, B.sC., Research Assistant

C. C. MALLIOS, M.D., Clinical Assistant school. The operating theatre measures some 9 by 5 by $4 \mathrm{~m}$ and incorporates an air-changing system which produces about five changes an hour. The patients were anaesthetized in the sitting position; anaesthesia was induced in adults by an intravenous injection of either propanidid (Epontol) or methohexitone (Brietal) or Althesin and maintained with nitrous oxide, oxygen, and halothane. In children anaesthesia was induced and maintained with nitrous oxide, oxygen, and halothane. The nitrous oxide and oxygen were supplied from a Walton Five apparatus via a temperature compensated vaporizer for halothane $(0-3 \%$; Cyprane Ltd.) and delivered to the patient via a nasal mask. The anaesthetist adjusted the pressure control-that is, the gas flow rate to the patient-and the halothane concentration for each individual patient's needs. The exhalation valve on the nasal mask was similarly adjusted but was usually in the fully open position.

When in use the scavenging devices were connected to a length of nylon tubing which ducted the exhaust gases to floor level. The devices tested were a disposable plastic syringe case fitted over the standard exhalation valve (Sniper and Murchison, 1972) and the Potter device. Potter's device is a metal anglepiece without a valve, having a separate channel for ducting of exhaled gases, and is substituted for the standard angle-piece and exhalation valve.

During anaesthesia the anaesthetist stood directly behind and above the patient, supporting the jaw with one hand and holding the nasal mask in position with the other. The dental surgeon stood in front and to the right of the patient.

Once adequate anaesthesia was achieved the patient's mouth was opened and a prop and dental pack were inserted. When all extractions were complete anaesthesia was discontinued and the patient was allowed to recover until conscious and then transferred to a separate recovery area.

\section{GAS CHROMATOGRAPHIC TECHNIQUE}

Air samples were taken into clean, grease-free, airtight $20-\mathrm{ml}$ glass syringes and capped with stainless-steel blind hubs and analysed within 90 minutes. Aliquots were introduced into a Perkin-Elmer series F11 gas chromatograph fitted with a $0 \cdot 25-\mathrm{ml}$ gas-sampling valve and flame ionization detector. Duplicate estimations were performed on each sample and compared with standards of known concentrations of halothane in nitrogen supplied by the British Oxygen Company.

\section{ATMOSPHERIC SAMPLING}

In order to allow for variations in anaesthetic level and operating time all samples were taken at the end of surgery just before discontinuance of anaesthesia. The atmosphere was sampled at three positions-level with the anaesthetist's nose, $15 \mathrm{~cm}$ from the expiratory valve of the nasal mask; level with the dental surgeon's nose, $15 \mathrm{~cm}$ from the expiratory valve of the nasal mask; and $2 \mathrm{~m}$ from the expiratory valve of the nasal mask, $1.3 \mathrm{~m}$ above the floor.

These measurements were made with the air-changing system off; with the air-changing system on; with the air-changing system on and a fan $3 \mathrm{~m}$ from the expiratory valve blowing in the direction of the patient's face; and with the air-changing system 

Degrees of Atmospheric Pollution with Halothane during Dental Anaesthesia. Results expressed as Parts per Million. (Figures in Parentheses are Range and
Number of Patients)

\begin{tabular}{|c|c|c|c|c|c|}
\hline & & $\begin{array}{l}\text { With Room } \\
\text { Ventilation Off }\end{array}$ & $\begin{array}{l}\text { With Room } \\
\text { Ventilation On }\end{array}$ & $\begin{array}{l}\text { With Room } \\
\text { Ventilation and } \\
\text { Local Fan On }\end{array}$ & $\begin{array}{c}\text { With Room } \\
\text { Ventilation and } \\
\text { Scavenging Device }\end{array}$ \\
\hline $\begin{array}{l}\text { Anaesthetist's level } \quad \ldots \\
\text { Dental surgeon's level } \quad \ldots \\
\text { Two metres from expiratory valve }\end{array}$ & $\because$ & $\begin{array}{l}23 \cdot 1(3 \cdot 1-58 \cdot 4 ; n=6) \\
68 \cdot 3(2 \cdot 7-941 \cdot 0 ; n=37) \\
13 \cdot 8(3 \cdot 1-36 \cdot 4 ; n=24)\end{array}$ & $\begin{array}{l}56 \cdot 8(16 \cdot 7-118 \cdot 1 ; n=18) \\
73 \cdot 77(3 \cdot 1-566 \cdot 7 ; n=19) \\
4 \cdot 3(1 \cdot 6-7 \cdot 1 ; n=5)\end{array}$ & $\begin{array}{l}46 \cdot 3(2 \cdot 7-296 \cdot 8 ; n=56) \\
45 \cdot 6(4 \cdot 5-310 \cdot 7 ; n=58) \\
6 \cdot 0(1 \cdot 6-17 \cdot 2 ; n=73)\end{array}$ & $\begin{array}{c}25 \cdot 2(1 \cdot 9-110 \cdot 0 ; n=56) \\
18 \cdot 5(1 \cdot 6-122 ; n=60) \\
5 \cdot 5(1 \cdot 5-12 \cdot 2 ; n=53)\end{array}$ \\
\hline
\end{tabular}

on and a scavenging device attached to the expiratory valve of the nasal mask.

\section{Results}

The degrees of atmospheric pollution so measured are presented in the table. The values obtained with the two scavenging devices were similar and are grouped together.

\section{Discussion}

This study shows that the anaesthetist and the dental surgeon are exposed to high concentrations of halothane in the atmosphere during procedures under general anaesthesia in the dental chair. These levels are greatly in excess of those occurring in general surgical operating theatres. Though scavenging devices reduced the contamination considerably it remained relatively high. It should be noted that there are no recommendations on acceptable levels of pollution of the atmosphere with volatile anaesthetics. It has, however, proved possible in surgical operating theatres to reduce halothane levels to the order of 1 p.p.m. by using scavenging devices (Witcher et al., 1971; Pfäffli et al., 1972). If 1 p.p.m. is taken as an acceptable level it is obvious that scavenging devices alone will not prove successful during dental anaesthesia. It is interesting to note that the use of the air-changing system and a local fan had little effect on contamination, perhaps as a result of local air eddies.

The evidence that exposure to low concentrations of volatile anaesthetics is harmful remains circumstantial (Spence, 1973). It seems reasonable, however, to take steps to exclude a possible hazard yto staff during dental extractions. Unfortunately no other method of general anaesthesia is entirely suitable for the present number of patients, many of whom are children, requiring treatment. The morbidity and mortality record of inhalation anaesthesia for dental outpatients is extremely good, and the method should not be abandoned lightly. Until the association between pollution and toxic effects on exposed personnel is clearly established, it may be better to support longterm measures for the prevention of dental decay than increase the hazard for patients who require general anaesthesia for their dental extractions.

We should like to thank Dr. C. J. F. Potter for his kind donation of one of his devices for use in this study. We also thank our colleagues in the anaesthetic department and the dental surgeons and nurses in the outpatient anaesthetic department at Kings' College Hospital Dental School for their kind co-operation.

\section{References}

Askrog, V. F., and Harvald, B. (1970). Nordisk Medicin, 83, 498. Cohen, E. N., Bellville, J. W., and Brown, B. W. (1971). Anesthesiology, 35,

Knill-Jones, R. P., Rodrigues, L. V., Moir, D. D., and Spence, A. A. (1972). Lancet, 1, 1326.

Pfäffli, P., Nikko, P., and Ahlman, K. (1972). British fournal of Anaesthesia, 44,230 .

Sniper, W., and Murchison, A. G. (1972). British fournal of Anaesthesia, 44, 1220 .

Spence, A. A. (1973). Annals of the Royal College of Surgeons of England, 52,

360.
Vaisman, A. I. (1967). Eksperimental'naya Khirugiya i Anesteziologiya, No. 3,
44. Witcher, C. E., Cohen, E. N., and Trudell, J. R. (1971). Anesthesiology, 35,

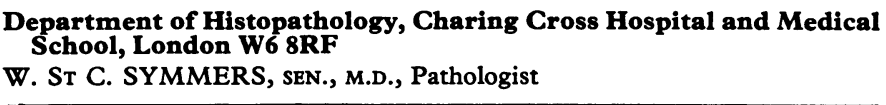

\section{Introduction}

A pathologist is sometimes in the position of seeming to be wise after an event that at the time of its currency was an equivocal and difficult clinical responsibility. The cases described in this paper could not have been recorded without the collaboration of the doctors who were concerned with the diagnosis and treatment of the patients' illnesses. It is my privilege to have the task of presenting their observations. No one should read these case reports without a thought of how he himself might have dealt with the situation at the time when his peers had to do so.

Amphotericin is a nephrotoxic drug (Siegel et al., 1970) and some degree of renal damage is almost inevitable when the drug is given intravenously. It has a sinister reputation in patients known to have kidney disease, and in the series of five fatal cases of fungal infection described in this paper the antibiotic was withheld or prescribed in too low a dosage be- 